\title{
INFLUÊNCIA DA TEORIA DE AGÊNCIA NA ALAVANCAGEM DAS EMPRESAS BRASILEIRAS
}

\section{INFLUENCE OF AGENCY THEORY OF LEVERAGE IN BRAZILIAN COMPANIES}

\author{
Luis Renato Junqueira \\ (FACE-UFMG/PUC Minas) \\ luisrj@yahoo.com.br \\ Carlos Henrique Soares \\ (Perfinaço Indústria e Comércio S.A) \\ chsoaresbh@yahoo.com.br \\ Maytê Cabral Mesquita \\ Pontifícia Universidade Católica de Minas Gerais \\ maytecam@yahoo.com.br
}

Luiz Alberto Bertucci (in memoriam) (FACE-UFMG)

Submissão: 04/11/2013 Aprovação: 26/02/2014

\section{RESUMO}

Esta pesquisa buscou avaliar se a adesão às práticas de Governança Corporativa, em qualquer um dos níveis estabelecidos pela BM\&FBovespa, reduz os conflitos de agência e, consequentemente, impacta no endividamento das empresas brasileiras de capital aberto. Para compor o modelo, foram adicionados outros fatores como lucratividade, tamanho e depreciação, uma vez que estes, teoricamente, também influenciam no volume de capital de terceiros das corporações. Os dados foram coletados por meio das demonstrações contábeis de 44 empresas que compõem o Índice Bovespa e dispostos no formato em painel, e o período analisado compreende os anos de 2004 a 2011. Foram testados três modelos: o de Estimador Comum, o de Efeitos Fixos e o de Efeitos Aleatórios, sendo este último o mais adequado, de acordo com os testes estatísticos realizados. No que tange à variável de Governança Corporativa, foi encontrada uma relação negativa, estatisticamente significativa, com o endividamento das empresas, confirmando a hipótese inicial. A Lucratividade também Revista Economia \& Gestão - v. 14, n. 35, abr./jun. 2014 
apresentou um resultado coerente com a teoria analisada indicando que corporações com maior lucratividade possuem menor volume de endividamento, por já suprir sua necessidade de caixa. Já as variáveis Tamanho e Depreciação não apresentaram resultados estatisticamente significativos e, portanto, não foram realizadas conclusões mais detalhadas.

Palavras-chave: Teoria de agência. Governança Corporativa. Estrutura de capital. Alavancagem. 


\begin{abstract}
the aim of this study was to assess if the adherence to the Corporate Governance practices, in any of the levels established by Bovespa, reduces the conflicts of agency and, consequently, impacts the indebtedness of Brazilian open capital companies. In order to set the model, other factors were added such as profitability, size, and depreciation, because these, in theory, also influence the amount of capital of the third parties of the corporations. Data were collected by means of financial statements of 44 companies that comprise the Bovespa Index and arranged in a panel, and the analyzed period was from 2004 to 2011. Three models were tested: the Common Estimator, the Fixed Effects and the Random Effects, being the latter the more appropriate, according to the statistical tests performed. Concerning the variable of Corporate Governance, a negative relatioxnship was found, statistically significant, with the debt of the companies, confirming the original hypothesis. The profitability also presented a result consistent with the analyzed theory indicating that corporations with higher profitability have less volume of debt, already supplying their need of cash. However, the variables Size and Depreciation did not present statistically significant results and, therefore, more detailed conclusions were not accomplished.
\end{abstract}

Keywords: Agency theory. Corporate Governance. Capital structure. Leverage. 


\section{INTRODUÇÃO}

Uma das decisões mais importantes para o gestor de uma empresa refere-se à composição da estrutura de capital da mesma, que segundo Ross, Westerfield e Jaffe (2002), compreende a combinação entre o volume de capital próprio, representado pelo capital dos acionistas ou proprietários, e a quantidade de capital de terceiros, composto pelos endividamentos e financiamentos.

Apesar de Modigliani e Miller (1958) apresentarem uma tese a respeito da irrelevância da estrutura de capital para o valor de mercado da companhia, o que foi objeto de muita discussão e provocou uma série de estudos futuros sobre o tema, hoje já se sabe que este tipo de decisão pode influenciar sim na valorização da organização. Tanto isto é verdade que os próprios Modigliani e Miller (1963) revisaram a sua posição e indicaram que um aumento no volume de capital de terceiros provocaria uma elevação no valor da firma, ocasionada pelo benefício tributário dos juros.

O capital próprio gera menos risco para a empresa, pois não possui data de vencimento e o mesmo não pode ser cobrado judicialmente. Entretanto, ele é mais oneroso, pois o acionista assume um risco maior. Portanto, esta decisão sobre a estrutura de capital envolve um dilema, assumir um risco maior em troca de um financiamento mais barato ou pagar mais pelos recursos, mas reduzir seu risco.

A estrutura de capital afeta e é influenciada por vários fatores, como o risco financeiro da companhia, os conflitos de agência entre os diversos stakeholders, na capacidade de investimento e na lucratividade da corporação, dentre outros.

Com relação aos conflitos de agência, Jensen e Meckling (1976) apontam dois tipos principais: um envolvendo o gestor e os acionistas e outro que abrange as relações entre credores e acionistas. Já Procianoy (1996) cita outro conflito, entre acionistas majoritários e minoritários, que é uma versão adaptada à realidade brasileira do conflito entre o gestor e os acionistas, pois no Brasil há semelhanças entre gestores e acionistas majoritários. O principal motivo da existência de todos estes conflitos é o fato de que cada agente possui interesses distintos, muitas vezes controversos, e cada qual buscará formas de fazer valer a sua vontade. Já a principal consequência gerada com a elevação de tais conflitos é a redução do valor de mercado da firma.

Neste sentido, os agentes mais envolvidos com a corporação podem buscar assumir compromissos cujos principais objetivos são demonstrar ao mercado como um todo de que suas decisões serão tomadas vislumbrando o bem comum médio de todos os interessados e Revista Economia \& Gestão - v. 14, n. 35, abr./jun. 2014 
ainda que eles atuam de forma a reduzir ao mínimo a assimetria informacional, apresentando a real situação da companhia, tanto atual quanto futura.

A Governança Corporativa vem justamente ao encontro da situação acima, pois representa um conjunto de procedimentos e normas de conduta que visam uma maior transparência das informações e a equidade no tratamento junto, principalmente, aos acionistas minoritários, os quais não controlam a companhia e possuem uma força relativamente pequena para fazer valer os seus interesses (ANDRADE e ROSSETTI, 2006).

Procianoy e Verdi (2009) tentaram relacionar a Governança Corporativa ao aumento no valor das ações das empresas. Na pesquisa em questão, os autores não conseguiram comprovar estatisticamente tal relação, mas identificaram que as ações das companhias que aderem aos novos mercados possuem maior liquidez.

Diante disso, é possível teorizar que organizações que adotam práticas de Governança Corporativa são mais valorizadas junto ao mercado e, portanto, têm seu custo de capital próprio reduzido, uma vez que proporcionam menos riscos aos investidores. Considerando que as decisões sobre a estrutura de capital levam em conta o binômio risco versus custo de capital, tais empresas podem optar por elevar seu volume de capital próprio, reduzindo seu risco, sem que isso represente uma elevação significativa no seu custo de capital.

No Brasil, a Bolsa de Valores, Mercadorias e Futuros de São Paulo - BM\&FBovespa - estabeleceu três níveis diferenciados de Governança Corporativa, os quais são gradativos com a seguinte sequência: Nível 1, Nível 2 e Novo Mercado. Como a adesão a qualquer nível é facultativa, pode-se inferir que esta prática pode proporcionar um diferencial para a empresa perante os investidores em geral.

Diante disso, o objetivo deste trabalho é verificar se as companhias brasileiras de capital aberto que aderiram a qualquer um dos níveis de Governança Corporativa, estabelecidos pela BM\&FBovespa, possuem um volume de endividamento menor do que aquelas pertencentes ao chamado Mercado Tradicional, considerando o período de análise compreendido entre os anos de 2004 e 2011.

Os resultados encontrados confirmaram o pressuposto acima, ou seja, as empresas brasileiras de capital aberto que fizeram, voluntariamente, a adesão em um dos níveis de Governança Corporativa estabelecidos pela Bolsa de Valores de São Paulo apresentaram uma volume de endividamento menor que as do Mercado Tradicional, no período de 2004 a 2011. Isso pode ser consequência da possível redução do custo de capital próprio que a Governança 
Corporativa promove, por meio da maior conformidade legal, prestação responsável de contas, transparência e equidade.

As conclusões apontam na direção de que a Governança Corporativa pode ser um importante mecanismo na redução dos Conflitos de Agência e que talvez existam mecanismos para que as empresas brasileiras reduzam seu custo de capital.

Este artigo, além da Seção 1 que trata da sua Introdução, está dividido em mais 6 seções. Na Seção 2 estão expostos os fundamentos da teoria sobre Estrutura de Capita, na Seção 3 são abordados aspectos sobre Governança Corporativa e Conflito de Agência, na Seção 4 são apontados outros aspectos que influenciam nas decisões sobre Estrutura de Capital. Na Seção 5 está descrita toda a Metodologia utilizada nesta pesquisa, na Seção 6 são apresentadas as Análises dos Resultados encontrados e na Seção 7 estão dispostas as conclusões a que se chegou com este estudo.

\section{ESTRUTURA DE CAPITAL}

Modigliani e Miller - MM (1958) apresentaram uma tese bastante interessante de que a Estrutura de Capital seria irrelevante para determinar o valor de mercado da empresa. Em outras palavras, a forma como a companhia é financiada não seria importante para os acionistas, mas sim como a mesma aplica seus recursos.

Tal proposição gerou muita discussão e impulsionou as pesquisas a respeito deste tema, sendo que algumas buscaram confirmar tal hipótese, mas a grande maioria teve como propósito justamente confrontar os argumentos apresentados pelos autores.

Os próprios Modigliani e Miller (1963) revisaram sua tese cinco anos mais tarde incluindo na análise o benefício gerado pela dedutibilidade fiscal dos juros provenientes das dívida, o que aumentaria o fluxo de caixa da empresa, tendo como consequência uma maior valorização da mesma. O problema é que se somente os benefícios tributários fossem considerados, poderíamos chegar a um caso extremo de que as organizações deveriam ser financiadas totalmente por capital de terceiros, o que não é plausível.

Diante disso, Jensen e Meckling (1976) acrescentaram que o risco de falência da corporação se eleva com o aumento da alavancagem, gerando custos diretos e indiretos relacionados a este processo. Então, o gestor deveria buscar um equilíbrio entre os benefícios 
e os custos gerados pelo endividamento, o que permite inferir sobre a existência de uma estrutura de capital ótima.

Miller (1977) afirma que, sob certas circunstâncias, a irrelevância da estrutura de financiamento sobre o valor de mercado pode permanecer, mesmo com a dedutibilidade tributária dos juros, já que as alíquotas de impostos que recaem sobre os investidores pessoais são diferentes. De qualquer forma, o autor alerta que este processo não pode ser generalizado, pois, depende de algumas condições definidas.

Com o passar do tempo, as pesquisas sobre estrutura de capital foram se multiplicando e, consequentemente, sofrendo evoluções, em que vários outros aspectos foram sendo incluídos e testados.

De Angelo e Masulis (1980) comprovaram que empresas com possibilidade de dedução tributária por meio de contas que não representam desembolso efetivo de caixa nem aumentam o risco da organização, como a depreciação ou amortização, tendem a limitar o benefício gerado pela dedutibilidade fiscal dos juros e, portanto, possuem um menor volume de capital de terceiros na sua estrutura de financiamento.

Um questionamento levantado por Miller (1977) sugere que a hipótese de que o benefício tributário dos juros estimula o endividamento das empresas é incompleta e ignora alguns aspectos relevantes. O autor indaga: como explicar o fato de que o nível de endividamento das corporações norte americanas não sofreu alteração significativa entre os anos de 1920 e 1950, mas as alíquotas dos impostos quase quintuplicaram no mesmo período?

Com isso, alguns autores inseriram nas análises outros fatores, sendo que um deles é a posse assimétrica de informações, cujos trabalhos mais citados são os de Leland e Pyle (1977) e Myers e Majluf (1984). Esta teoria afirma que os diversos agentes do mercado não possuem as mesmas informações, sendo que os gestores internos sempre têm mais conhecimento sobre a real situação da organização, tanto atual quanto futura, do que os investidores externos. Diante disso, estes tentam descobrir a real situação da firma decifrando as decisões tomadas pelos gestores, sendo que estas são refletidas nos preços que os investidores estão dispostos a pagar pelas ações.

Pela lógica, o gestor busca atender aos interesses dos atuais acionistas. Se isto for verdade, a emissão de novas ações somente ocorrerá caso estas estejam supervalorizadas. Sabendo disso, os investidores reagem negativamente a uma decisão deste tipo, reduzindo o valor de mercado da empresa. Já a contratação de dívida emite sinais de que o gestor acredita 
que a firma irá gerar fluxo de caixa suficiente para quitar o compromisso assumido e, portanto, os agentes externos interpretam isso como um sinal positivo (SMITH JR., 1986).

Outro fator que foi relacionado ao tema estrutura de capital é o dinamismo ambiental. Simerly e Li (2000) concluíram que corporações que atuam num mercado dinâmico e volátil tendem a conter um volume menor de dívida, pois a instabilidade se torna um obstáculo para se conseguir arcar com os compromissos financeiros assumidos. Já em ambientes mais estáveis, é possível estimar os fluxos de caixa futuros com uma precisão maior, permitindo que compromissos financeiros com valor fixo e data pré-determinada possam ser assumidos sem gerar grandes problemas nem elevar significativamente o risco de falência da companhia.

\section{GOVERNANÇA CORPORATIVA E CONFLITOS DE AGÊNCIA}

A teoria de agência estuda os relacionamentos existentes entre diversos agentes que envolvem uma organização. Estes relacionamentos ocorrem, principalmente, quando uma ou mais pessoas, chamadas de "principal", delegam a terceiros, denominados de "agentes", a possibilidade destes tomarem decisões em seu nome. Tal delegação dá liberdade ao agente, mas o principal espera que seus interesses sejam defendidos. O problema é que os agentes também possuem seus próprios desejos, os quais nem sempre convergem com os do principal. Neste ponto, pode surgir um conflito de agência, que se for muito grande, se refletirá negativamente no valor de mercado da companhia.

Foram identificados por Jensen e Meckling (1976) dois tipos de conflitos de agência. Os que ocorrem entre gestores e acionistas e os entre credores e acionistas. Procianoy (1996) acrescenta o conflito entre os acionistas majoritários e os minoritários, mais comum no Brasil, uma vez que a gestão, muitas vezes, é realizada pelo acionista majoritário, e este pode se beneficiar em detrimento dos minoritários.

Uma forma de os acionistas controlarem as ações dos gestores é por meio de um monitoramento mais intenso, verificando todas as decisões tomadas pelos agentes. Entretanto, isto não é prático, pois os acionistas delegam tais decisões justamente por falta de tempo, interesse ou capacidade. Se for para controlar tanto, o próprio acionista assume a gestão da sua corporação, não necessitando delegar isso a outra pessoa. Todo este trabalho gera o chamado custo de monitoramento.

Outros custos relacionados a esta teoria são os custos de comprometimento, os quais ocorrem quando o gestor se compromete a limitar suas próprias decisões para transmitir Revista Economia \& Gestão - v. 14, n. 35, abr./jun. 2014 
confiança aos acionistas. O problema é que esta atitude pode impedir que alguns bons negócios sejam concretizados, pois podem ultrapassar alguns limites inicialmente impostos.

Como nenhum contrato é perfeito, ou seja, não se consegue abranger todas as situações que porventura possam existir, sempre haverá mais um custo, denominado perda residual, que refere-se àquelas situações que não foram cobertas pelos contratos de monitoramento e comprometimento.

O conflito entre gestores e acionistas ocorre devido ao fato de que os primeiros controlam o dinheiro da empresa, mas não a financiam, a não ser se forem também acionistas, sendo que neste último caso, o seu comprometimento financeiro não será de 100\%. Em outras palavras, eles podem usar um capital que não foi aplicado por eles, sendo que isso pode significar benefícios não pecuniários, como viagens, salas e carros de luxo, mordomias ou ainda projetos de investimento com motivação pessoal e não financeira.

Para se defender das situações acima, os acionistas possuem dois mecanismos: desvalorizar as ações da empresa, reduzindo seu valor de mercado, ou criar mecanismos que limitam tais atitudes. Hart e Moore (1995) apontam que o aumento significativo da alavancagem da companhia gera um compromisso financeiro periódico, o que limita as ações dos gestores.

Entretanto, esta estratégia pode ser arriscada, pois ao mesmo tempo que impede que gastos desnecessários sejam concretizados, pode impossibilitar a realização de investimentos que agregam valor, justamente pela limitação da folga financeira (HARRIS e RAVIV, 1990).

Com o mesmo objetivo de reduzir os conflitos e custos de agência, uma proposta que está em pleno desenvolvimento no mundo são as práticas de Governança Corporativa. Silva e Leal (2007) lembram que a adesão a tais práticas por parte das corporações é voluntária e representa a intenção dos gestores de agirem conforme os interesses dos acionistas.

Brandão e Bernardes (2005) mencionam que a Governança Corporativa tem como base quatro pilares: a) compliance (conformidade legal); b) accountability (prestação responsável de contas); c) disclosure (transparência); d) feirness (equidade). Em outras palavras, respeita a lei, evita fraudes contábeis, reduz a assimetria de informação e trata todos os atores (acionistas e credores) de forma igualitária, respeitando a participação, os direitos e deveres de cada um.

A BM\&FBovespa ajudou na consolidação da Governança Corporativa no Brasil ao criar os três níveis de comprometimento, cada qual com seus padrões específicos, sendo que as exigências vão aumentando com os níveis. São eles: Nível 1, Nível 2 e Novo Mercado. A 
adesão a qualquer um dos níveis é voluntária e busca demonstrar ao mercado que a companhia está disposta a defender os interesses dos investidores de forma igualitária, o que tende a reduzir os conflitos de agência. A adesão não precisa ser gradual, sendo que a corporação pode participar do Novo Mercado sem ter passado pelos níveis inferiores.

Catapan, Colauto e Barros (2013) relacionam a Governança Corporativa ao desempenho da economia, uma vez que o desenvolvimento das empresas é influenciado pelo primeiro fator e está diretamente relacionado ao segundo. Esse aspecto demonstra a importância da distribuição de autoridade, da responsabilidade e do controle organizacional.

Foram realizadas várias pesquisas relacionando a adesão aos níveis de Governança Corporativa ao endividamento da organização. Cicogna, Valle e Toneto Junior (2005) indicaram que a maioria dos estudos conclui que a demanda e o valor das ações das companhias aumentam e seu custo de capital reduz com a adoção das práticas de Governança Corporativa. Silva Junior, Junqueira e Bertucci (2009) concluíram que as empresas brasileiras do setor elétrico que faziam parte de qualquer um dos níveis de Governança Corporativa apresentaram menores índices de endividamento que as demais.

A estrutura de propriedade das empresas também é um fator que pode influenciar nas decisões sobre a sua alavancagem. Além disso, no Brasil as organizações têm como característica uma maior concentração de capital, se comparadas com companhias de países mais desenvolvidos. Peixoto e Buccini (2013) até identificaram uma pequena queda na concentração de capital entre 2004 e 2008, mas mesmo assim ela é bem acentuada, ficando acima de 55\% do capital votante em poder do maior acionista. Além disso, os autores concluíram que tal concentração gera um efeito negativo sobre o valor e a rentabilidade das empresas.

Considerando esse aspecto, Procianoy e Schnorrenberger (2004) relacionaram a estrutura de propriedade com o endividamento de empresas brasileiras entre 1995 e 2000 . A conclusão dos autores foi de que uma maior concentração na estrutura de controle gera um menor volume de endividamento, uma vez que os controladores possuem uma maior aversão ao risco, já que a empresa pode ser a sua maior riqueza pessoal. 


\section{OUTROS FATORES INFLUENCIADORES DA ESTRUTURA DE CAPITAL}

Uma dúvida motivou vários estudos a respeito da estrutura de capital: quais fatores são determinantes no processo de escolha do nível de endividamento das corporações? Neste sentido, Titman e Wessels (1988) analisaram oito variáveis que eles consideraram que tinham possibilidade de interferir neste processo: valor dos ativos que servem como garantia, benefícios fiscais sem ser via juros, oportunidades de crescimento, especialização do setor, classificação do setor, tamanho da organização, volatilidade dos retornos, rentabilidade dos negócios.

De todas elas, somente a especialização do setor e o tamanho da organização apresentaram resultados estatisticamente significativos. Apesar disso, as demais variáveis não foram totalmente descartadas pelos autores, uma vez que há uma consistência muito forte na fundamentação teórica. A sugestão foi a realização de outros estudos com alterações no processo metodológico.

Seguindo este mesmo caminho, Perobelli e Famá (2002) fizeram uma pesquisa baseada nos mesmos fatores utilizados por Titman e Wessels (1988), mas utilizando apenas empresas brasileiras. Além disso, o capital de terceiros foi dividido em curto e longo prazos, ocasionando duas análises distintas.

Com relação à dívida de curto prazo, três fatores foram estatisticamente significativos e apresentaram relações inversamente proporcionais ao endividamento: tamanho, oportunidade de crescimento e rentabilidade dos negócios. Já a análise referente à dívida de longo prazo, nenhuma variável foi estatisticamente significativa.

Diante das sugestões apresentadas acima, foram incluídas outras variáveis no modelo para isolar o efeito destas sobre o endividamento e podermos avaliar o impacto da adesão a um dos níveis de Governança Corporativa sobre a alavancagem sem a interferência dos mesmos. Os fatores incluídos neste estudo foram: rentabilidade, tamanho e depreciação, este último representa os benefícios fiscais sem ser via dívida.

Não há consenso a respeito da existência da melhor estrutura de capital para uma empresa específica, sendo que vários aspectos podem ser analisados e várias conclusões podem ser alcançadas dependendo da amostra, metodologia e variáveis consideradas. Este trabalho pretende contribuir com a teoria de finanças corporativas trazendo novos resultados e também novos questionamentos. 


\section{METODOLOGIA}

A utilização de métodos estatísticos para tentar responder a pergunta desta pesquisa faz com que ela seja classificada como quantitativa. Além disso, é possível afirmar que a mesma tem características funcionalistas, de acordo com a classificação de Burrel e Morgan (1979). A técnica de pesquisa utilizada foi o Survey, uma vez que foram coletados um volumoso conjunto de dados.

O procedimento metodológico adotado foi instrumento estatístico análise de regressão múltipla com dados em painel, que reúne as características dos dados cross section e das séries temporais ao mesmo tempo. Em outras palavras, é possível avaliar as diferenças entre vários indivíduos ao longo de determinado período (GUJARATI, 2000).

Os dados coletados são anuais e foram extraídos dos Demonstrativos Contábeis Consolidados publicados pelas próprias empresas pertencentes à amostra e retirados do site da Bolsa de Valores de São Paulo e da Comissão de Valores Mobiliários.

\subsection{Amostra}

A amostra foi composta por 44 empresas pertencentes ao Índice Bovespa, elevando a sua representatividade no volume de negociações efetuadas no mercado financeiro brasileiro. O período analisado corresponde a 8 anos, iniciando em 2004 e finalizando em 2011. Foram excluídas as companhias do setor financeiro, pois o endividamento deste tipo de empresa apresenta muitas particularidades, o que poderia distorcer a análise. Portanto, podemos concluir que o número de observações corresponde a 352 (44 empresas x 8 anos). A listagem das corporações analisadas, em ordem alfabética, está no Quadro 1 a seguir:

Quadro 1: Empresas que compõem a amostra

\begin{tabular}{|l|l|l|l|}
\hline ALL Am. Latina & Comgás & JBS & Sabesp \\
\hline Ambev & Copel & Klabin & Siderúrgica Nacional \\
\hline Aracruz / Fibria & CPFL & Light & Souza Cruz \\
\hline Bradespar & Cyrela & Lojas Americanas & TAM \\
\hline Brasil Telecom & Duratex & Lojas Renner & Telefônica Vivo \\
\hline Braskem & Eletrobrás & Natura & Telemar \\
\hline BRF Food & Eletropaulo & Net & TIM \\
\hline CCR Rodovias & Embraer & Pão de Açúcar & Tran. Paulista \\
\hline Celesc & Gafisa & Petrobrás & Ultrapar \\
\hline Cemig & Gerdau & Redecar & Usiminas \\
\hline Cesp & Gol & Rossi & Vale \\
\hline
\end{tabular}

Fonte: elaborado pelos autores

Revista Economia \& Gestão - v. 14, n. 35, abr./jun. 2014 
5.2 Variável dependente: Endividamento

Não há um consenso a respeito da mensuração do endividamento de uma organização, entretanto, nesta pesquisa optou-se por seguir o modelo utilizado por Lang, Ofek e Stulz (1996) e Silveira, Barros e Famá (2003), em que o endividamento total (curto + longo prazos) é dividido pelo ativo total da organização.

$$
E N D I V=\frac{\text { Dívida de Curto Prazo }+ \text { Dívida de Longo Prazo }}{\text { Ativo Total }}
$$

5.3 Variáveis independentes

a) Governança Corporativa - GC

Trata-se de uma variável dummy ou binária, em que foi atribuído o valor de 1 para as empresas que pertencem a qualquer um dos níveis diferenciados de Governança Corporativa estabelecidos pela BM\&FBovespa (Nível 1, Nível 2 ou Novo Mercado) e 0 para aquelas que fazem parte do chamado Mercado Tradicional.

É importante ressaltar que foi considerada a data em que a companhia aderiu a um dos níveis. Em outras palavras, se uma empresa aderiu a qualquer nível em meados de 2009, foi atribuído 0 entre os anos de 2004 a 2008 e valor 1 para os anos de 2009 a 2011.

b) Rentabilidade

De acordo com a Pecking Order Theory, as organizações tendem a ter uma ordem de preferência de captação de recursos financeiros, sendo primeiramente os lucros gerados pela própria atividade operacional, em seguida títulos de dívida, depois títulos híbridos e, por fim, emissão de novas ações (MYERS, 1984).

Diante disso, é possível inferir que corporações que conseguem auferir maior rentabilidade tendem a apresentar menores volumes de endividamento, uma vez que a própria atividade operacional supre boa parte da sua necessidade de capital. Essa variável é mensurada, conforme Simerly e Li (2000) e Goyal, Lehn e Racic (2002), por meio da divisão entre o resultado operacional e o ativo total da corporação.

$$
\text { RENT }=\frac{\text { Lucro Líquido }}{\text { Ativo Total }}
$$


c) Tamanho

Vários estudos sobre estrutura de capital apontam que o tamanho da corporação é uma variável que exerce influência sobre a sua alavancagem. A hipótese levantada é de que as empresas maiores possuem um patrimônio mais valioso e que pode ser utilizado como garantia de empréstimos e, portanto, apresentariam maior facilidade para obter financiamento com capital de terceiros. Em resumo, quanto maior o tamanho da firma maior tende a ser sua alavancagem.

Neste trabalho, a variável Tamanho foi mensurada por meio da metodologia apresentada por autores como Goyal, Lehn e Racic (2002) e Perobelli e Famá (2002), que é o logaritmo natural do valor do Ativo Total.

$$
T A M=L N(\text { Ativo Total })
$$

d) Depreciação

Uma das grandes vantagens do endividamento, segundo Modigliani e Miller (1963), é a dedutibilidade tributária dos juros. Já a depreciação é uma conta contábil que não representa desembolso, mas que também oferece o benefício da redução da carga tributária, sem elevar o risco da organização, o que não ocorre com o capital de terceiros.

Diante disso, podemos concluir que as firmas com um elevado montante de depreciação não teria tantos benefícios fiscais com a alavancagem e, portanto, tais fatores teriam uma relação negativa entre si, conforme comprovado por De Angelo e Masulis (1980).

A depreciação foi relativizada pelo ativo total da empresa:

5.4 Modelos Analisados

$$
\text { DEPREC }=\frac{\text { Depreciação }}{\text { Ativo Total }}
$$

Esta pesquisa utilizou a metodologia de Dados em Painel que, segundo Greene (2000) e Johnston e DiNardo (1997), permite a utilização de três tipos de modelos a saber: o de estimador comum, o de efeitos fixos e o de efeitos aleatórios. Portanto, foram considerados estes três modelos, sendo que a escolha do mais adequado foi realizada por meio de testes estatísticos, detalhados mais adiante.

O modelo de Estimador Comum possui a seguinte equação:

$$
\text { ENDIV }=\beta_{0}+\beta_{1} G C+\beta_{2} \text { Rent }+\beta_{3} \text { Tam }+\beta_{4} \text { Deprec }+\varepsilon_{i t}
$$


Em que: ENDIV = endividamento (variável dependente);

$\beta_{0}=$ intercepto;

$\beta_{j}=$ coeficientes das variáveis independentes;

$\mathrm{GC}=$ Governança Corporativa;

Rent $=$ rentabilidade;

Tam= tamanho;

Deprec $=$ depreciação.

Já o segundo modelo testado foi o de Efeitos Fixos e apresentou a seguinte equação:

$$
\text { ENDIV }=\alpha_{i}+\beta_{1} G C+\beta_{2} \text { Rent }+\beta_{3} \text { Tam }+\beta_{4} \text { Deprec }+\varepsilon_{i t}
$$

Em que: $\alpha_{i}=$ efeito individual da $i$-ésima empresa.

Por fim, o último modelo avaliado foi o de Efeitos Aleatórios, cuja equação foi:

$$
\text { ENDIV }=\beta_{0}+\beta_{1} G C+\beta_{2} \text { Rent }+\beta_{3} \text { Tam }+\beta_{4} \text { Deprec }+\mu_{i}+\eta_{i t}
$$

Em que: $\boldsymbol{\mu}_{i}+\boldsymbol{\eta}_{i t}=\boldsymbol{\varepsilon}_{i t}$

$$
\mu_{i}=\text { efeito individual da } i \text {-ésima empresa. }
$$

\subsection{Testes de Hipótese}

Foram realizados alguns testes estatísticos para validar as variáveis incluídas no modelo, para escolher qual o modelo mais adequado e também para validar os resultados encontrados.

\subsubsection{Teste de Colinearidade Perfeita e Multicolinearidade}

Dois problemas apontados por Wooldridge (2003) que devem ser evitados são a colinearidade perfeita e a multicolinearidade. O primeiro ocorre quando um fator é múltiplo de outro, o que impossibilita o cálculo dos coeficientes $\beta_{\mathrm{j}}$, pois a mesma variável explicativa seria incluída em duplicidade e em unidades de medidas distintas.

Já o segundo problema refere-se à correlação forte, mas não perfeita, entre variáveis independentes. Esse fato eleva a variância dos coeficientes estimados, diminuindo sua precisão.

Para detectar as situações acima, foi construída uma matriz de correlação entre as variáveis independentes para tentar encontrar alguma correlação com valor absoluto maior que 0,50, para que, se necessário, seja excluída uma das duas variáveis. 


\subsubsection{Teste F para a escolha entre os modelos}

Para se escolher o modelo mais adequado para este trabalho, foram feitos três testes estatísticos. O primeiro foi um teste F para optar entre os modelos de Estimador Comum e de Efeitos Fixos. O segundo também foi um teste $\mathrm{F}$ para comparar os modelos de Estimador Comum com o de Efeitos Aleatórios. Por fim, realizou-se o Teste Hausman, para escolher entre os modelos de Efeitos Fixos ou o de Efeitos Aleatórios.

Então, no primeiro teste, as hipóteses analisadas foram:

$\mathrm{H}_{0}$ : modelo de estimador comum;

$\mathrm{H}_{1}$ : modelo de efeitos fixos.

Já o segundo teste realizado considerou as seguintes hipóteses foram:

$\mathrm{H}_{0}$ : modelo de estimador comum;

$\mathrm{H}_{1}$ : modelo de efeitos aleatórios.

Em ambos os testes acima, caso o valor do Teste F encontrado for superior ao Fcrítico, devemos rejeitar a hipótese nula e escolher o modelo de H1, caso contrário, é melhor utilizar o modelo de estimador comum.

\subsubsection{Teste de Hausman}

Este teste é utilizado para comparar os Modelos de Efeitos Fixos com o Modelo de Efeitos Aleatórios, sendo que as hipóteses testadas são:

$\mathrm{H}_{0}$ : modelo de efeitos aleatórios;

$\mathrm{H}_{1}$ : modelo de efeitos fixos.

Caso o valor do Teste de Hausman for superior ao valor crítico da função QuiQuadrado, deve-se rejeitar a hipótese nula e optar pelo Modelo de Efeitos Fixos, caso contrário a melhor opção é o Modelo de Efeitos Aleatórios. 


\subsubsection{Teste t para a validação das variáveis}

Para analisar a validade das variáveis do modelo, foi utilizado o Teste t, que, conforme Gujarati (2000), testa cada fator independente individualmente, considerando as hipóteses:

$$
\begin{aligned}
& \mathrm{H}_{0}: \beta_{\mathrm{j}}=0 \\
& \mathrm{H}_{1}: \beta_{\mathrm{j}} \neq 0
\end{aligned}
$$

Ressaltamos que os softwares computacionais já calculam o $p$-value, que representa a probabilidade do coeficiente ser igual a zero, ou seja, estatisticamente não significativo. Como limite de significância para todos os testes citados, foi estabelecido o percentual de $95 \%$, em outras palavras, aceita-se uma margem de erro de $5 \%$.

\section{ANÁLISE DOS RESULTADOS}

O objetivo desta pesquisa é descobrir se a adesão voluntária, por parte das corporações, a um dos níveis diferenciados de Governança Corporativa estabelecidos pela $\mathrm{BM} \& \mathrm{FBovespa}$ proporciona uma redução no custo do capital próprio, ocasionando num menor endividamento das mesmas.

A amostra é composta por dados dispostos em painel de 44 empresas durante 8 anos, iniciando em 2004 e finalizando em 2011.

Na Tabela 1 a seguir está apresentada a estatística descritiva das variáveis utilizadas nesta pesquisa, para conhecermos melhor cada uma delas.

\begin{tabular}{lcccc}
\multicolumn{5}{c}{ Tabela 1 - Estatística Descritiva das Variáveis } \\
\hline & $\boldsymbol{E N D}$ & $\boldsymbol{T A M}$ & $\boldsymbol{R E N T}$ & $\boldsymbol{D E P R E C}$ \\
\hline Média & 0,2687 & 16,2515 & 0,0676 & 0,0396 \\
Mediana & 0,2555 & 16,3175 & 0,0576 & 0,0322 \\
Mínimo & 0,0001 & 13,3494 & $-0,1798$ & 0,0000 \\
Máximo & 0,7774 & 20,2110 & 0,3890 & 0,1735 \\
Variância & 0,0202 & 1,4984 & 0,0049 & 0,0010 \\
Desvio-padrão & 0,1421 & 1,2241 & 0,0707 & 0,0320 \\
Observações & 352 & 352 & 352 & 352 \\
\hline
\end{tabular}

*Foi excluído o fator GC por ser uma variável binária.

Fonte - Elaborada pelos autores. 
Para confirmar a não existência de colinearidade perfeita ou multicolinearidade, foi construída a matriz de correlação entre as variáveis independentes, cujos resultados encontrados foram:

Tabela 2 - Matriz de Correlação entre as Variáveis Independentes

\begin{tabular}{lrrrr}
\hline & \multicolumn{1}{c}{$\boldsymbol{T A M}$} & $\boldsymbol{R E N T}$ & DEPREC & $\boldsymbol{G C}$ \\
\hline TAM & 1 & & & \\
RENT & $-0,1882$ & 1 & & \\
DEPREC & 0,0760 & $-0,0196$ & 1 & \\
GC & $-0,1056$ & $-0,1623$ & $-0,3686$ & 1 \\
\hline
\end{tabular}

Fonte - Elaborada pelos autores.

Não foi identificado nenhum indício de correlação significativa a qual aconselhasse a retirada de alguma variável do modelo analisado. Todas as correlações apresentadas na Tabela 1 acima indicaram um valor absoluto inferior a 0,5 , demonstrando a inexistência deste problema na amostra selecionada.

Posteriormente foi escolhido, por meio de testes estatísticos, o modelo mais adequado dentre os três inicialmente considerados: o de Estimador Comum, o de Efeitos Fixos e o de Efeitos Aleatórios. Os resultados encontrados foram os seguintes:

Tabela 3 - Resultados dos testes para a escolha do modelo

\begin{tabular}{l|c|c|c|c|c}
\hline \multicolumn{1}{c|}{ Hipótese } & Teste & $\begin{array}{c}\text { Valor } \\
\text { Crítico }\end{array}$ & $\begin{array}{c}\text { Valor } \\
\text { Calculado }\end{array}$ & $p$-value & Escolha \\
\hline $\begin{array}{l}\mathrm{H}_{0}: \text { Estimador comum } \\
\mathrm{H}_{1}: \text { Efeitos fixos }\end{array}$ & Teste $\mathrm{F}$ & 1,4205 & 8,9795 & 0,0000 & Efeitos Fixos \\
\hline $\begin{array}{l}\mathrm{H}_{0}: \text { Estimador comum } \\
\mathrm{H}_{1}: \text { Efeitos aleatórios }\end{array}$ & Teste $\mathrm{F}$ & 1,4205 & 7,0097 & 0,0000 & Efeitos Aleatórios \\
\hline $\begin{array}{l}\mathrm{H}_{0}: \text { Efeitos aleatórios } \\
\mathrm{H}_{1}: \text { Efeitos fixos }\end{array}$ & Hausman & 9,4877 & 3,5238 & 0,4743 & Efeitos Aleatórios \\
\hline
\end{tabular}

Fonte - Elaborada pelos autores

De acordo com a Tabela 2 acima, é possível concluir que o modelo mais adequado neste caso foi o de Efeitos Aleatórios, em que a heterogeneidade individual de cada empresa não é correlacionada com as variáveis independentes e, portanto, pode ser incluída no termo de erro. 
Em seguida, rodou-se a regressão utilizando o software Eviews, sendo que os resultados encontrados foram:

Tabela 4 - Resultados do Modelo de Efeitos Aleatórios

\begin{tabular}{c|c|c|c}
\hline \multicolumn{4}{c}{ Variável Dependente: Endividamento } \\
\hline Intercepto & Gov. Corporativa & Rentabilidade & Tamanho \\
\hline $\begin{array}{c}0,2966 \\
(0,0352)\end{array}$ & $\begin{array}{c}-0,0626 \\
(0,0013)\end{array}$ & $\begin{array}{c}-0,5800 \\
(0,0000)\end{array}$ & $\begin{array}{c}0,0033 \\
(0,7001)\end{array}$ \\
\hline \hline Depreciação & $\mathrm{R}^{2}$ & $\mathrm{R}^{2}$ Ajustado & $\begin{array}{c}\text { Número de } \\
\text { Observações }\end{array}$ \\
\hline $\begin{array}{c}0,0275 \\
(0,9310)\end{array}$ & 0,5546 & 0,5495 & 352 \\
\hline
\end{tabular}

Fonte - Elaborada pelos autores.

Nota - Os valores entre parênteses representam os $p$-values dos coeficientes.

Embora tenham sido calculados os efeitos individuais das empresas, tais coeficientes não foram objeto de análise e, portanto, omitidos neste trabalho.

$\mathrm{O} \mathrm{R}^{2}$ e o $\mathrm{R}^{2}$ Ajustado apresentaram resultados satisfatórios, sendo 0,5546 e 0,5495 respectivamente. Tais resultados reforçam o modelo e apontam para a existência de influência destes fatores no volume de endividamento das companhias analisadas.

\subsection{Governança Corporativa}

A hipótese levantada neste trabalho foi a de que a adoção das práticas de Governança Corporativa sinaliza ao mercado de que o gestor e os acionistas majoritários procuram atuar do forma transparente e tratam os demais investidores igualitariamente. Tal situação reduz os conflitos de agência diminuindo o custo do capital próprio, que é menos arriscado do que o capital de terceiros. Com isso, espera-se que as empresas que se inserem voluntariamente num dos níveis de Governança Corporativa tendem a possuir um nível de endividamento menor do que as pertencentes ao Mercado Tradicional.

Esta proposição é reforçada pelo artigo Silva Junior, Junqueira e Bertucci (2009), no qual foram analisadas 51 empresas brasileiras do setor energético, no ano de 2008, cuja conclusão foi de que há uma relação negativa entre Governança Corporativa e alavancagem.

Os cálculos apontaram que as firmas que aderiram a qualquer um dos níveis de Governança Corporativa possuem realmente um endividamento menor, uma vez que o coeficiente encontrado foi negativo de -0,0626. Além disso, este valor se apresentou Revista Economia \& Gestão - v. 14, n. 35, abr./jun. 2014 
estatisticamente significativo mesmo a um nível de significância de 99\%, pois o $p$-value foi de 0,0013 .

Portanto, os resultados encontrados foram ao encontro da hipótese inicialmente levantada, de que as empresas que adotaram as práticas de Governança Corporativa tenderiam a apresentar menores níveis de endividamento, se comparadas a outras pertencentes ao Mercado Tradicional.

\subsection{Rentabilidade}

Myers (1984) apresentou a teoria da Pecking Order cujo pressuposto é de que os gestores possuem uma ordem de preferência na captação de recursos financeiros para financiar as atividades da organização. Segundo esta teoria, a ordem de captação seria a seguinte: 1) lucros retidos; 2) títulos de dívidas; 3) títulos conversíveis; 4) emissão de novas ações. Diante disso, espera-se que empresas mais lucrativas tenham menores índices de endividamento, pois somente o farão caso os recursos provenientes da atividade operacional tenham se esgotado.

Os resultados confirmaram tal hipótese, uma vez que o coeficiente relacionado à rentabilidade foi negativo, $-0,5800$, conforme Tabela 3 . O $p$-value $(0,0000)$ demonstra que tal relação é estatisticamente significativa, mesmo se considerarmos um limite de $99 \%$ para o nível de certeza. Assim, pode-se concluir pela importância da rentabilidade sobre o processo de escolha da estrutura de capital.

\subsection{Tamanho}

O tamanho da companhia é um dos fatores mais citados como determinantes da estrutura de capital de uma empresa. Segundo Titman e Wessels (1988), esta variável possui uma relação positiva com a alavancagem, pois as organizações que têm maior volume de ativos podem usá-los como garantias de empréstimos e, portanto, possuem mais capacidade de se endividar.

O resultado apresentado na tabela 3 confirma esta hipótese, uma vez que o coeficiente encontrado foi positivo, 0,0033. Entretanto, esta análise deve ser feita com cautela, uma vez que o coeficiente não foi estatisticamente significativo, já que seu p-value foi de 0,7001 . 
Portanto, nesta pesquisa não foi possível confirmar o tamanho como um fator determinante da estrutura de capital de uma empresa.

\subsection{Depreciação}

Segundo a Tradeoff Theory, um dos principais benefícios do endividamento é a economia gerada pela dedutibilidade tributária dos juros. Entretanto, existem algumas contas contábeis, como a depreciação, amortização e exaustão, que também geram este benefício fiscal sem representar um desembolso de caixa e sem elevar o risco da companhia.

Então, se a organização já tiver um alto volume de depreciação, amortização ou exaustão, o benefício fiscal gerado pelos juros da dívida não será tão expressivo. Portanto, teoricamente, estes dois fatores possuem relação negativa.

Neste trabalho, o coeficiente da variável Depreciação se apresentou positivo, 0,0275, contrariando a hipótese inicial. Entretanto, o p-value de 0,9310 indica que este resultado não é estatisticamente significativa e, portanto, não é possível fazer maiores inferências sobre este resultado.

Este fato vai ao encontro do estudo de Miller (1977), que indicou que mesmo com a introdução da permissão de dedutibilidade fiscal da depreciação no início da década de 1960 nos EUA, as companhias elevaram sua alavancagem. 


\section{CONCLUSÃO}

Esta pesquisa teve como propósito relacionar a redução do conflito de agência, representado pela adesão, por parte das companhias, a um dos níveis diferenciados de Governança Corporativa estabelecidos pela BM\&FBovespa, à alavancagem financeira das mesmas.

O pressuposto é de que a transparência e equidade pregadas pela Governança Corporativa reduzam o custo do capital próprio, que é menos arriscado para a organização, permitindo que esta diminua seu endividamento. Portanto, espera-se que empresas pertencentes ao Nível 1, Nível 2 ou ao Novo Mercado tenham menor volume de capital de terceiros do que as demais.

Foram incluídos no modelo outros fatores que, segundo diversos estudos já realizados, também exercem influência sobre a estrutura de capital das corporações. São eles: rentabilidade, tamanho e depreciação.

A amostra foi composta por 44 empresas que compõem o Índice Bovespa, e os dados foram anuais no período compreendido entre os anos de 2004 a 2011, totalizando 8 anos de análise. Não foram inseridas companhias pertencentes ao setor financeiro, devido a particularidades na sua estrutura de capital.

Como os dados coletados reúnem características tanto de dados cross section, em que 44 corporações diferentes foram estudadas, quanto de séries temporais, considerando 8 anos de análise, os mesmos foram dispostos no formato em painel.

Primeiramente, para verificar se as variáveis independentes apresentam colinearidade perfeita ou multicolinearidade, foi construída uma Matriz de Correlação entre os fatores explicativos, para avaliar se há necessidade de retirada de algum deles. Como não foram encontrados resultados absolutos maiores que 0,50, concluiu-se que não há indícios destes dois problemas.

Dados em painel permitem a utilização de alguns modelos distintos, sendo que neste trabalho foram testados: a) o de Estimador Comum; b) o de Efeitos Fixos; c) o de Efeitos Aleatórios. O primeiro teste $\mathrm{F}$ apontou que o modelo de Efeitos Fixos foi melhor do que o de Estimador Comum. O segundo teste F indicou o modelo de Efeitos Aleatórios como melhor do que o de Estimador Comum. Com isso, o modelo de Estimador Comum foi descartado. Por fim, foi realizado o Teste de Hausman para comparar os modelos de Efeitos Fixos com o de 
Efeitos Aleatórios. A conclusão foi de que o modelo mais adequado para esta pesquisa é o de Efeitos Aleatórios.

Os resultados confirmaram o pressuposto inicialmente levantado, pois indicaram que as companhias que aderiram a um dos níveis diferenciados de Governança Corporativa apresentaram um menor volume de endividamento. Além disso, o coeficiente encontrado apresentou-se estatisticamente significativo.

Portanto, foi possível inferir que a adesão às práticas de Governança Corporativa reduz os conflitos de agência e, consequentemente, diminui o custo do capital próprio, que são recursos menos arriscados para a corporação. Portanto, empresas pertencentes a tal segmento podem financiar suas atividades com um nível de capital de terceiros menos.

A rentabilidade foi uma variável que revelou correlação negativa, conforme o esperado, com o volume de endividamento, e seu coeficiente foi estatisticamente significativo. Este resultado corrobora a teoria da Pecking Order, que defende a ideia de que há uma ordem de preferência para a captação de recursos, qual seja: 1) lucros retidos; 2) títulos de dívida; 3) títulos conversíveis; 4) emissão de novas ações. Portanto, organizações cuja atividade gera uma elevada rentabilidade não necessitam de tantos recursos de terceiros.

Um fator considerado importante no processo de alavancagem das corporações é o seu tamanho, pois teoricamente, aquelas que possuem um volume de ativos maior têm maior capacidade de endividamento, pois podem oferecê-los como garantia. O coeficiente encontrado confirma a hipótese inicial de relação positiva entre o tamanho e a alavancagem. Entretanto, este fator não foi estatisticamente significativo, o que nos impede de fazer maiores inferências a seu respeito.

Outra variável incluída no modelo foi a depreciação. Segundo a Tradeoff Theory, o maior benefício do capital de terceiros seria a dedutibilidade fiscal dos juros. Entretanto, a conta contábil depreciação apresenta o mesmo efeito sem representar desembolso para a empresa nem elevar seu nível de risco financeiro. Portanto, organizações com alto volume de depreciação tendem a contrair menor volume de dívida. O resultado encontrado contraria este tese, pois apresentou uma relação positiva entre estes dois fatores. Apesar disso, o coeficiente não foi estatisticamente significativo, impedindo que façamos uma análise mais aprofundada sobre a variável. Este resultado tem respaldo no estudo de Miller (1977) que demonstrou que o início da permissão da dedutibilidade fiscal da depreciação no início da década de 1960 não reduziu a alavancagem das empresas norte-americanas, pelo contrário, ocorreu uma elevação. 
Como sugestão para pesquisas futuras, recomendamos a separação da amostra nos diferentes níveis de Governança Corporativa existentes no Brasil, quais sejam: Nível 1, Nível 2 e Novo Mercado. Com isso, seria possível identificar como a redução do endividamento observada neste estudo se comporta dependendo do nível de comprometimento da empresa com as práticas de Governança Corporativa.

De uma forma geral, conclui-se que as empresas brasileiras que aderiram às práticas de Governança Corporativa, em qualquer um dos níveis estabelecidos pela BM\&FBovespa, apresentaram menores volumes de dívida em sua estrutura de capital. Isto pode indicar uma redução no conflito de agência, o que diminuiria o custo do capital próprio, tornando-o mais atrativo. 


\section{REFERÊNCIAS BIBLIOGRÁFICAS}

ANDRADE, Adriana; ROSSETTI, José Paschoal. Governança corporativa: fundamentos, desenvolvimento e tendências. 2. ed. São Paulo: Atlas, 2006.

BOLSA DE VALORES, MERCADORIAS E FUTUROS DE SÃO PAULO BM\&FBOVESPA. Níveis Diferenciados de governança corporativa. Disponível em <www.bmfbovespa.com.br> Acesso em 25/09/2012.

BRANDÃO, Mônica Mansur; BERNARDES, Patrícia. Governança corporativa e o conflito de agência entre os acionistas majoritários e os minoritários no sistema de decisões estratégicas das corporações brasileiras. XXIX Encontro Nacional da ANPAD - ENANPAD, 2005, Brasília. Anais... Brasília, 2005.

BURREL, G.; MORGAN, G. Sociological paradigms and organizational analysis. London: Heinemann, 1979.

CATAPAN, A.; COLAUTO, R. D.; BARROS, C. M. E. A relação entre a Governança Corporativa e o desempenho econômico-financeiro de empresas de capital aberto do Brasil. Contabilidade, Gestão e Governança, Brasília, v. 16, n. 2, p. 16-30, mai/ago, 2013.

De ANGELO, Harry; MASULIS, Ronald W. Leverage and dividend irrelevancy under corporate and personal taxation. The Journal of Finance, v. 36, n. 2, p. 453-64, May 1980.

GOYAL, Vidhan K.; LEHN, Kenneth e RACIC, Stanko. Growth opportunities and corporate debt policy: the case of U.S. defense industry. Journal of Financial Economics, v. 64, n. 1, p. 35-59, Apr. 2002.

GREENE, William H. Econometric analysis. 4. ed. Rio de Janeiro: Prentice-Hall, 2000.

GUJARATI, Damodar N. Econometria básica. São Paulo: Makron Books, 2000. 
HARRIS, Milton e RAVIV, Artur. Capital structure and the informational role of debt. The Journal of Finance, v. 45, n. 2, p. 321-49, June 1990.

HART, Oliver e MOORE, John. Debt and seniority: an analysis of the role of hard claims in constraining management. American Economic Review, v. 85, n. 3, p. 567-85. June 1995.

JENSEN, Michael C.; MECKLING, William H. Theory of the firm: managerial behavior, agency costs, and ownership structure. Journal of Financial Economics, v. 3, n.4, p. 305-60, Oct. 1976.

JOHNSTON, Jack e DiNARDO, John. Econometric methods. 4th. ed. New York: McGrawHill, 1997.

LANG, Larry, OFEK, Eli; STULZ, Rene M. Leverage, investment, and firm growth. Journal Financial Economics, v. 40, n. 1, p. 3-29, Jan. 1996.

LELAND, Hayne E.; PYLE, David H. Informational asymmetries, financial structure, and financial intermediation. The Journal of Finance, v. 32, n. 2, p. 371-87, May 1977.

MILLER, Merton. Debt and taxes. The Journal of Finance, v. 32, n. 2, p. 261-75, May 1977.

MODIGLIANI, Franco e MILLER, Merton H. The cost of capital, corporate finance and the theory of investment. American Economic Review, v. 48, n. 3, p. 261-97, June 1958.

MODIGLIANI, Franco; MILLER, Merton H. Corporate income taxes and the cost of capital: a correction. American Economic Review, v. 53, n. 3, p. 433-43, June 1963.

MYERS, Stewart C. The capital structure puzzle. The Journal of Finance, v. 39, n. 3, p. 57592, July 1984.

MYERS, Stewart C.; MAJLUF, Nicholas S. Corporate financing and investment decisions when firms have information that investors do not have. Journal of Financial Economics, v. 13, n. 2, p. 187-222, June 1984. 
PEIXOTO, F. M.; BUCCINI, A. R. A. Separação entre propriedade e controle e sua relação com desempenho e valor de empresas brasileiras: onde estamos? Revista de Contabilidade e Organizações, São Paulo, v. 17, p. 48-59, 2013.

PEROBELLI, Fernanda Finotti Cordeiro; FAMÁ, Rubens. Determinantes da estrutura de capital: aplicação a empresas de capital aberto brasileiras. Revista de Administração, São Paulo, v. 37, n. 3, p. 33-46, jul-set. 2002.

PROCIANOY, Jairo Laser. Dividendos e tributação: o que aconteceu após 1988-1989. Revista de Administração, São Paulo, v. 31, n. 2, p. 7-18, abril/junho, 1996.

PROCIANOY, J. L.; SCHNORRENBERGER, A. A influência da estrutura de controle nas decisões de estrutura de capital das companhias brasileiras. Revista Brasileira de Economia, Rio de Janeiro, v. 58, n. 1, p. 121-146, 2004.

PROCIANOY, J. L.; VERDI, R. S. Adesão aos novos mercados da Bovespa: Novo Mercado, Nível 1 e Nível 2 - Determinantes e Consequências. Revista Brasileira de Finanças, v. 7, n. 1, p. 107-136, 2009.

ROSS, Stephen A.; WESTERFIELD, Randolph W.; JAFFE, Jeffrey F. Administração financeira: corporate finance. 2. ed. São Paulo: Atlas, 2002.

SILVA, André Luiz Carvalhal; LEAL, Ricardo Pereira Câmara. Governança corporativa: evidências empíricas no Brasil. São Paulo: Atlas, 2007.

SILVA JUNIOR, Reinilson Rodrigues da; JUNQUEIRA, Luis Renato; BERTUCCI, Luiz Alberto. A relação entre a adoção das práticas de Governança Corporativa e a alavancagem financeira das empresas brasileiras do setor energético no ano de 2008. Gestão e Sociedade. v. 3, n. 6, p. 315-334, jul-dez 2009. 
SILVEIRA, Alexandre Di Miceli da; BARROS, Lucas Ayres B. de C.; FAMÁ, Rubens. Estrutura de governança e valor das companhias abertas brasileiras. Revista de Administração de Empresas, São Paulo, v. 43, n. 3, p. 50-63, jul./set. 2003.

SIMERLY, Roy L.; LI, Mingfang. Environmental dynamism, capital structure and performance: a theorical integration and an empirical test. Strategic Management Journal, v. 21, n.1, p. 31-49, Jan. 2000.

SMITH JR. Clifford W. Investment banking and capital acquisition process. Journal of Financial Economics, v. 15, p. 3-29, 1986.

TITMAN, Sheridan e WESSELS, Roberto. The determinants of capital structure choice. The Journal of Finance, v. 48, n. 1, p. 1-19, Mar. 1988.

WOOLDRIDGE, Jeffrey M. Introductory econometrics. Michigan: Michigan State University, IE - Thomson, 2003. 